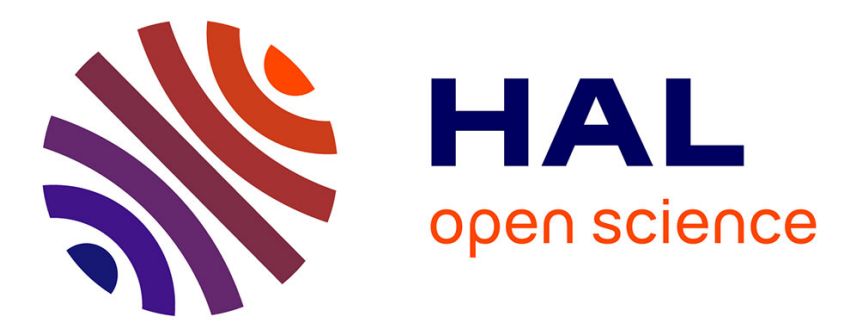

\title{
Enhancement of mechanical strength of particleboard using environmentally friendly pine (Pinus pinaster L.) tannin adhesives with cellulose nanofibers
}

Juqing Cui, Xiaoning Lu, Xiaojian Zhou, Laurent Chrusciel, Yuhe Deng, Handong Zhou, Shangwu Zhu, Nicolas Brosse

\section{To cite this version:}

Juqing Cui, Xiaoning Lu, Xiaojian Zhou, Laurent Chrusciel, Yuhe Deng, et al.. Enhancement of mechanical strength of particleboard using environmentally friendly pine (Pinus pinaster L.) tannin adhesives with cellulose nanofibers. Annals of Forest Science, 2015, 72 (1), pp.27-32. 10.1007/s13595014-0392-2 . hal-01284153

\section{HAL Id: hal-01284153 \\ https://hal.science/hal-01284153}

Submitted on 7 Mar 2016

HAL is a multi-disciplinary open access archive for the deposit and dissemination of scientific research documents, whether they are published or not. The documents may come from teaching and research institutions in France or abroad, or from public or private research centers.
L'archive ouverte pluridisciplinaire HAL, est destinée au dépôt et à la diffusion de documents scientifiques de niveau recherche, publiés ou non, émanant des établissements d'enseignement et de recherche français ou étrangers, des laboratoires publics ou privés. 


\title{
Enhancement of mechanical strength of particleboard using environmentally friendly pine (Pinus pinaster L.) tannin adhesives with cellulose nanofibers
}

\author{
Juqing Cui • Xiaoning Lu • Xiaojian Zhou • \\ Laurent Chrusciel • Yuhe Deng • Handong Zhou • \\ Shangwu Zhu $\cdot$ Nicolas Brosse
}

Received: 9 November 2013 / Accepted: 29 May 2014 / Published online: 19 June 2014

(C) INRA and Springer-Verlag France 2014

\begin{abstract}
- Context Condensed tannins have been successfully used as substitutes for phenol in the production of resins for wood products. However, the enhancement of the properties of tannin-based resins with nontoxic and cost effective additives is of great interest.

- Methods In the present work, the performance enhancement of tannin-based particleboards with cellulose nanofibers was investigated.

- Results In presence of $2 \%$ of cellulose nanofibers, the viscosity of tannin-based adhesives and the internal bonding strength (IB) of the corresponding particleboards were increased from 350 to $5,462 \mathrm{mPa} \cdot \mathrm{s}$ and from 0.85 to $0.98 \mathrm{MPa}$ respectively. The modulus of elastic (MOE) and modulus of rupture (MOR) of the resins were also notably increased while thickness swelling (TS) of the panels was not affected.

- Conclusion The addition of cellulose nanofibers to tannin adhesives is an effective method for the production of high performance particleboards. Tannin-based adhesive containing $2 \%$ of cellulose nanofibers exhibits the best mechanical strength. Key message The addition of cellulose nanofibers into tanninbased adhesives notably enhanced the mechanical properties of the wood particleboards produced. The formulation
\end{abstract}

Handling Editor: Jean-Michel Leban

J. Cui $\cdot$ X. Lu $\cdot$ Y. Deng $\cdot$ H. Zhou $\cdot$ S. Zhu

College of Materials Science and Engineering, Nanjing Forestry

University, No. 159 Longpan Road, Xuanwu District,

Nanjing 210037, China

X. Zhou $\cdot$ L. Chrusciel $\cdot$ N. Brosse $(\bowtie)$

LERMAB, University of Lorraine, Boulevard des Aiguillettes - BP

239, F-54500 Vandoeuvre-lès-Nancy, France

e-mail:

J. Cui $\cdot$ S. Zhu

Dare Technology Co., Ltd., No. 95 West Jinling Road,

Danyang 212300, China containing $2 \%(w / w)$ of cellulose nanofibers exhibited the best mechanical strength.

Keywords Tannins · Wood adhesives · Cellulose nanofibers · Environmentally friendly $\cdot$ Mechanical strength

\section{Introduction}

Wood adhesives play a key role for the production of woodbased panels such as plywood, fiberboard, particleboard, and related structural wood composite because of high-efficient utilization of wood and agri-foresty residues. The quality of bonding and enhancement of the properties of wood-based panels mainly depends on adhesives qualities (Takemura 2010; Stoeckel et al. 2013). Currently, formaldehyde-based synthetic adhesives such as urea-formaldehyde resin (UF), phenol-formaldehyde resin (PF), and melamine formaldehyde (MF) are the predominant adhesives for the manufacture of various wood panels. Because of formaldehyde emissions, it has been demonstrated that formaldehyde-based adhesives are not environmentally friendly products. Formaldehyde emissions are due to residual unreacted formaldehyde and to slow adhesive hydrolysis under hot/humid conditions during the production and use of panel (Han et al. 2008; Sari et al. 2010; He et al. 2012). In the USA, interior wood-based panels have been adapted to enacted regulations by the California Air Resources Board (CARB) that regulates formaldehyde emissions from wood-based panels. Various green building rating systems have addressed "low-emitting" and "renewable materials" for the building materials and adhesives (Ruffing et al. 2010). Therefore, environmentally friendly or green wood adhesives (Pizzi 2000; Imam et al. 2001; Ibrahim et al. 2008; Lei et al. 2008; Kajaks et al. 2012) derived from renewable resources (i.e., tannins, soy protein, lignin 
adhesives, etc.) have been a topic of considerable interest for many years and constitute an area of active research.

Condensed tannins are generally extracted from the bark of various trees like mimosa (Mimosa pigra), quebracho (Schinopsis lorentzii), or pine (Pinus). It was demonstrated that condensed tannins are both chemically and economically interesting for the preparation of adhesives and that they could be successfully used as substitutes for phenol in the production of resins (Pizzi et al. 1993a, 1993b; Li et al. 2004; Pichelin et al. 2006; Kim 2009; Moubarik et al. 2010; Patel et al. 2012). In the last decade, several approaches have been developed to produce wood panels with low formaldehyde emissions using tannin-based adhesives. Recently, it has been reported that grape pomace from wine industry is also an important source of tannins for the production of environmentally friendly tannin adhesives (Ping et al. 2011, 2012). At present, pine tannin and pecan nut pith tannin adhesives fortified with a synthetic resin such as polymeric $4,4^{\prime}$-diphenyl methane diisocyanate (MDI) are used commercially for woodbased panel (Pizzi et al. 1993a). However, the cost and the toxicity of MDI limit its broad utilization.

Cellulose nanofibers (CNF), because of their renewability, nanoscale dimensions, high surface area, and good mechanical response to stress, attracted substantial attention for the production of nanocomposites with enhanced properties (Bhatnagar and Sain 2005; Habibi et al. 2010). The significant enhancement of the mechanical properties of a composite reinforced with CNF can be justified by the high value of Young's modulus of pure crystalline cellulose domains (about $150 \mathrm{GPa}$ ). While a considerable number of publications regarding the reinforcement of polymers with nanocellulose can be found, literature on cellulose-reinforced adhesives suitable for wood bonding is quite scarce. Veigel et al. (2012) described the production of particleboards prepared with nanocellulosereinforced urea-formaldehyde and melamine-ureaformaldehyde adhesives. Richter et al. (2009) discussed the application of CNF for reinforcing polyurethane and polyvinyl acetate latex wood adhesives. However, to the best of our knowledge, the reinforcement of a tannin-based adhesive has never been reported in the literature.

In this paper, the production and the characterization of tannin-based adhesives reinforced with cellulose nanofibers are described. Particleboards with improved mechanical strength were produced.

\section{Materials and methods}

\subsection{Materials}

Commercial tannins from pine (Pinus pinaster L.) were used to prepare tannin adhesives. Cellulose nanofibers
(KY100) were produced by Intelligent Chemicals Pty Ltd (China). Their solid content, diameter, and length are $25 \%, 10 \sim 50 \mathrm{~nm}$, and 400 600 um respectively. One to two percent (wt) suspension of CNF were prepared through ultrasonication treatment before mixing with tannins. Solid paraformaldehyde as hardener was purchased from Sigma-Aldrich Company.

\subsection{Characterization of tannin adhesives with cellulose nanofibers}

The viscosity of the resins was determined using a rotational viscometer (Brookfield DV-II+Viscometer) at $25^{\circ} \mathrm{C}$ for tanninbased adhesives without and with CNF. About $10 \mathrm{~g}$ of a $30 \%$ $(w / w)$ lyophilised tannin solution, $5 \%$ of powdered paraformaldehyde on a dry and solid tannin matter content basis were added to a test tube with or without CNF. The tube was placed in a water bath, which was maintained at boiling temperature (just below $100{ }^{\circ} \mathrm{C}$ ) at normal atmospheric pressure. The time taken to reach the gel point was recorded during constant stirring with the aid of a wire spring and a stopwatch. The test was duplicated, and the average value is reported.

About $5 \mathrm{~g}$ of a $40 \%(w / w)$ tannin solution, $5 \%$ of powdered paraformaldehyde on a dry and solid tannin matter content basis were added and mixed together. Twenty-five milligrams of the mixture was coated in one side of two small wood chips $(5 \mathrm{~mm} \times 20 \mathrm{~mm})$ for the measurement of the modulus of elasticity by on a thermal mechanical analyzer with a TA controller (Mettler TMA 40) equipped with a STARe data processing software. The experiments were conducted under the following operating parameters: a heating rate of $10{ }^{\circ} \mathrm{C} / \mathrm{min}$ from 25 to $250{ }^{\circ} \mathrm{C}$ and three-point bending TMA mode.

\subsection{Wood particleboard preparation and testing}

Triplicates of single-layer particleboards of $340 \times 300 \times$ $14 \mathrm{~mm}^{3}$ dimension were prepared using particles of beech (Fagus sylvatica) and Norway spruce (Picea abies) at $28 \mathrm{~kg} /$ $\mathrm{cm}^{2}$ maximum pressure, $195{ }^{\circ} \mathrm{C}$ press temperature, and 7.5 min press time. Ten percent ( $w / w$ based on dry particles) of adhesive resin solid was loaded. All particleboards were

Table 1 Viscosity and gelation time of the adhesives and internal bonding strength of the particleboards prepared with and without cellulose nanofibers

\begin{tabular}{llll}
\hline & $\begin{array}{l}\text { Viscosity } \\
(\mathrm{mPa} \cdot \mathrm{s})\end{array}$ & $\begin{array}{l}\text { Gelation } \\
\text { time (s) }\end{array}$ & $\begin{array}{l}\text { Internal bonding } \\
\text { strength (MPa) }\end{array}$ \\
\hline Tannin & $350 \pm 8$ & $328 \pm 16$ & $0.85 \pm 0.03$ \\
Tannin-1\% CNF & $1,550 \pm 15$ & $336 \pm 15$ & $0.96 \pm 0.04$ \\
Tannin-2\% CNF & $5,462 \pm 24$ & $345 \pm 17$ & $0.98 \pm 0.05$ \\
Tannin-3\% CNF & $11,270 \pm 43$ & $340 \pm 19$ & $0.86 \pm 0.04$ \\
\hline
\end{tabular}




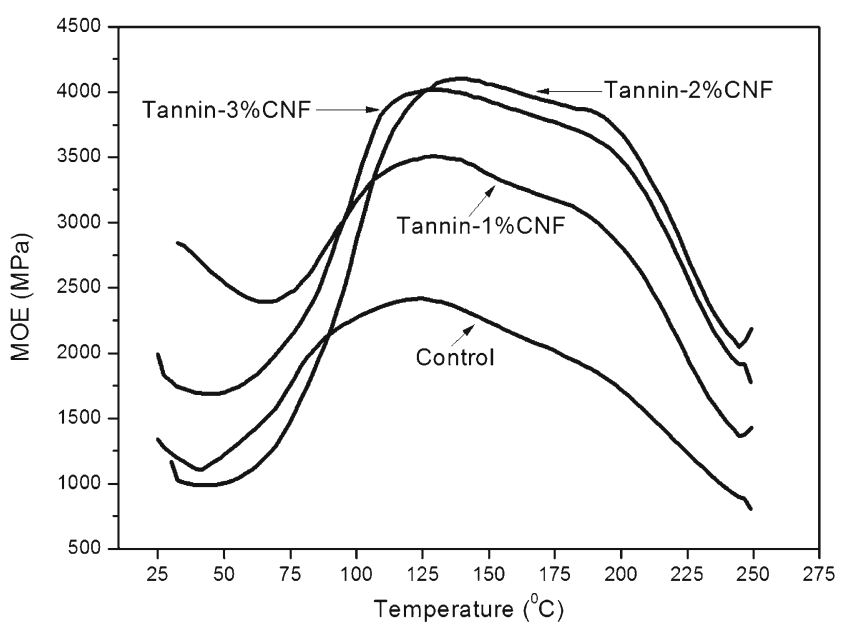

Fig. 1 Thermomechanical analysis of tannins adhesives with and without cellulose nanofibers

tested to measure the internal bonding strength in the dry state according to the relevant international standard European Norm EN 312, wood particleboard-specifications. The modulus of elasticity and modulus of rupture were, respectively, determined according to the European Norm EN 310. The thickness swelling determined after 2-, 6-, and 24-h immersion in cold water was carried out according to the European Norm EN 317.

\section{Results}

3.1 Viscosity of tannin adhesives modified with adjunction of cellulose nanofibers

The viscosity of tannin adhesive in absence and presence of different amount of cellulose nanofibers is shown in Table 1. It is clearly seen that it strongly increased as the nanocellulose concentration increased. With $3 \%$ of cellulose, a solid-like viscoelastic behavior was observed.

\subsection{Gelation time of tannin adhesives modified} with adjunction of cellulose nanofibers

Gel time is defined as the point at which the polycondensates formed by the reaction of a tannin solution and formaldehyde become an elastic, rubbery solid. This is an indication of the reactivity of the sites of tannin molecules toward formaldehyde. The experimental results concerning the determination of gel time with and without addition of CNF are shown in Table 1. All formulations exhibited a similar gel time (near $340 \mathrm{~s}$ ) and a slight increase in the presence of nanofibers corresponding to a decrease of the tannin reactivity.

3.3 Mechanical properties of particleboard glued with tannin adhesives modified with adjunction of cellulose nanofibers

The mechanical strength of bonded wood joints has been scanned by a thermomechanical analysis in bending according to a technique already reported in a previous work (Laigle et al. 1998). The variations of the modulus of elasticity as a function of an increasing temperature are given in Fig. 1. Interestingly, addition of nanofibers in the resins yielded a noticeable improvement in the maximum value of the modulus of elasticity. It appears from Fig. 1 that $2 \%$ of CNF gives the best performance with a maximum modulus of elasticity value of 4,100 MPa. A further increase in the $\mathrm{CNF}$ content led to a slight decrease in the performance of the resin. Tanninbased adhesives containing $0-3 \%$ of CNF were also tested for application to wood particleboard. Table 1 also gives the internal bonding strength of panels which are a direct measurement of the performance of the adhesive. The data showed
Fig. 2 Modulus of elasticity and modulus of rupture of particleboard glued with tanninbased adhesives with or without cellulose nanofibers

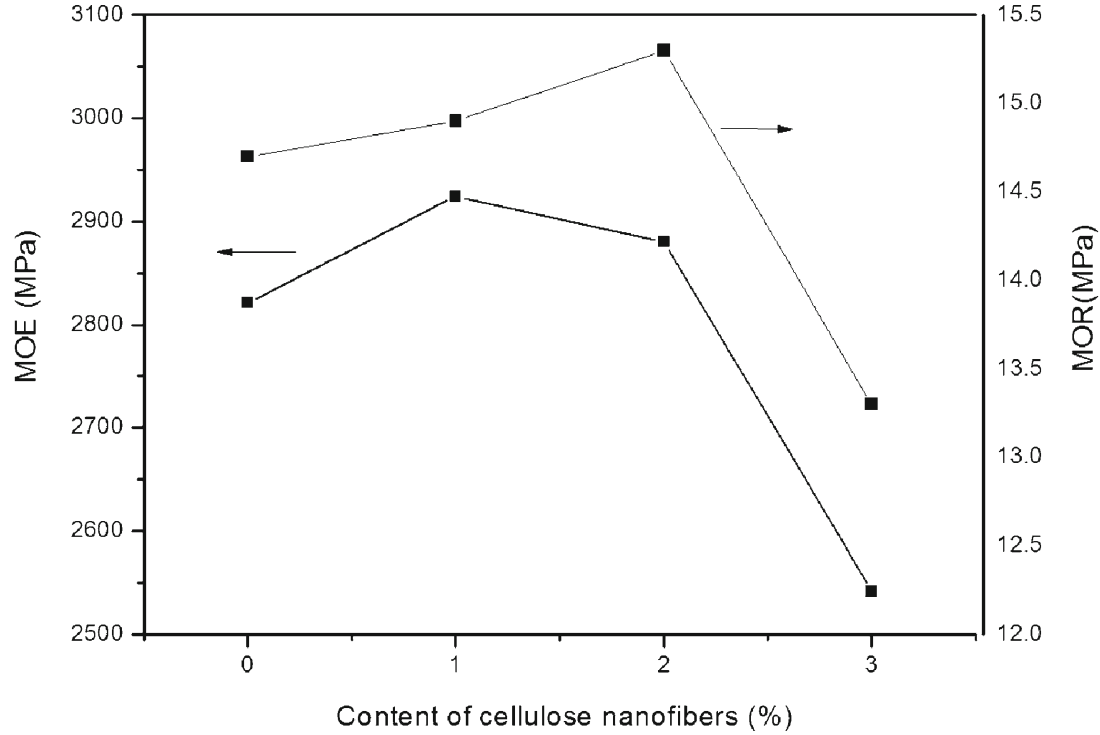


Fig. 3 Thickness swelling of tannin-based particleboards with or without cellulose nanofibers

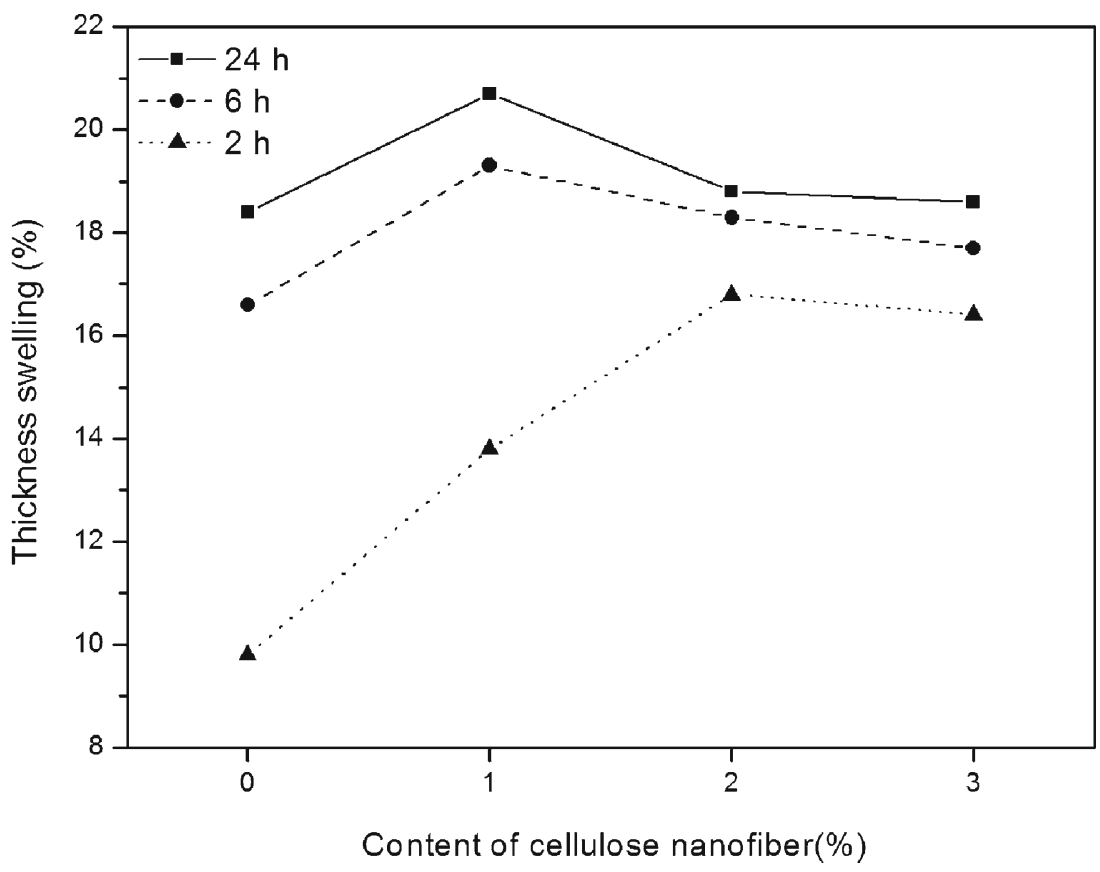

that the addition of CNF in the resin formulation greatly improved the panel strength; the addition of $2 \%$ of $\mathrm{CNF}$ yielded the highest internal bonding strength value ( $1 \mathrm{MPa}$ ). It clearly appears from Fig. 2 that the modulus of elasticity and the modulus of rupture values of the particleboards slightly increased with the addition of low amounts of CNF (1-2 \%) but dramatically decreased for a higher nanofibers content (3\%). All these results are in accordance with the thermomechanical analysis experiments previously exposed.

3.4 Thickness swelling of particleboard glued with tannin adhesives modified with adjunction of cellulose nanofibers

Finally, the water resistance of wood particleboards bonded with tannin-based resin reinforced with $\mathrm{CNF}$ was evaluated. The thickness swelling (\%) after immersion of the wood panels (prepared with and without CNF) in cold water during 2, 6, and $24 \mathrm{~h}$ is displayed in Fig. 3. After $2 \mathrm{~h}$ of immersion, a dramatic swelling was observed with an increasing content in CNF (until $2 \%$ ). However, for longer immersion durations (6 and $24 \mathrm{~h}$ ), the presence of CNF has a little or no effect on the swelling thickness.

\section{Discussion}

Viscosity is a measurement of the resistance to gradual deformation by shear stress, which largely influences at the first stage of the distribution of the adhesive on the wood particle surface. The high viscosity observed in presence of nanofibers may result from strong hydrogen bond network between CNF and from their interaction with tannin molecules. However, the gelation time results showed that the presence of nanofibers does not seem to have a significant impact on the tannin reactivity toward crosslinking reactions.

The results of thermomechanical analysis and mechanical strength of particleboard prepared with or without CNF confirm that (1) addition of CNF in a tannin-based adhesive formulation notably enhanced its mechanical properties and (2) the optimum CNF content was established at $2 \%$. Chun et al. (2011) described the preparation of ultrastrength nanopapers using cellulose nanofibrils. The authors explained the high tensile strength of the nanopapers observed by a three-dimension network between the CNF and the paper components (siloxane). Similar papers (Zimmermann et al. 2010; Eyholzer et al. 2012; Hrabalova et al. 2011) reported the utilization of nanocellulose for polymer matrix reinforcement.

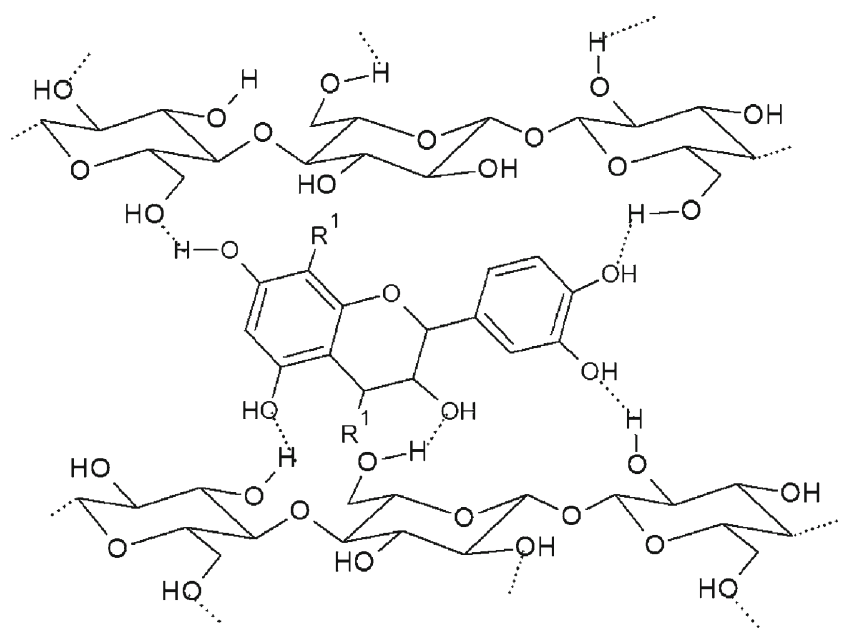

Fig. 4 Schematic diagram of the H-bond network between CNF and flavanols moieties 
The dramatic increase of both viscosity and mechanical strength of the resin in presence of $2 \% \mathrm{CNF}$ can be rationalized by a strong $\mathrm{H}$-bond network involving $\mathrm{CNF}$ and flavanol units (Fig. 4); this network should form a tight complex besides the high Young's modulus of CNF in bond line. The observation of thickness swelling can probably be explained by the presence of a large number of hydroxyl groups on the surface of CNF, increasing the kinetic of the swelling of the material. Nevertheless, the actual water resistance of the panels seems not to be notably affected by the presence of CNF. Thus, it can be concluded that panels bonded with tannin adhesives including cellulose nanofibers could be used for interior applications. Utilization of a synthetic crosslinker such as polymeric 4,4'-diphenyl methane diisocyanate (pMDI) could be considered in future investigations for exterior purposes.

\section{Conclusions}

The experimental results obtained in this research work have shown that the addition of cellulose nanofibers to tannin adhesives for the production of particleboards could notably enhance the mechanical properties of the panels produced. The presence of cellulose nanofibers in tannin adhesives does not largely influence the polycondensation reaction of tannins but remarkably increases the viscosity of the resin. Thermomechanical analysis results have demonstrated that tannin adhesives containing $2 \%$ of cellulose nanofibers exhibited the best mechanical resistance. The measurements of the internal bonding strength, modulus of elasticity, and modulus of rupture of particleboards produced with these tannin adhesives confirmed the thermomechanical analysis. The water resistance of the panels seems not to be notably affected by the presence of cellulose nanofibers.

Acknowledgments The authors gratefully acknowledge financial support from Jiangsu Planned Projects for Postdoctoral Research Funds (1302042B), Cooperative Innovation Fund of Jiangsu Province (BY2013006-02), the National High Technology Research and Development Program of China (863 Program) (2012AA03A204), Forestry Industry Research Special Funds for Public Welfare Projects (201104042), and A Project Funded by the Priority Academic Program Development of Jiangsu Higher Education Institutions (PAPD). The authors are grateful for the financial support of this research from CPER 2007-2013 "Structuration du Pôle de Compétitivité Fibres Grand'Est" and from the French National Research Agency through the Laboratory of Excellence ARBRE (ANR-12- LABXARBRE-01).

\section{References}

Bhatnagar A, Sain M (2005) Processing of cellulose nanofiber-reinforced composites. J Reinf Plast Comp 24:1259-1268

Chun SJ, Lee SY, Doh GH, Lee S, Kim HJ (2011) Preparation of ultrastrength nanopapers using cellulose nanofibrils. J Ind Eng Chem 17:521-526
Eyholzer C, Tingaut P, Zimmermann T, Oksman K (2012) Dispersion and reinforcing potential of carboxymethylated nanofibrillated cellulose powders modified with 1-hexanol in extruded poly(lactic acid) (PLA) composites. J Poly Environ 20:1052-1062

Habibi Y, Lucia LA, Rojas OJ (2010) Cellulose nanocrystals: chemistry, self-assembly, and applications. Chem Rev 110:3479-3500

Han TL, Kumar RN, Rozman HD, Daud WRW (2008) Influence of process variables on the reactivity of low formaldehyde emission urea-formaldehyde resin. Poly-Plast Technol 47:551-557

He ZK, Zhang YP, Wei WJ (2012) Formaldehyde and VOC emissions at different manufacturing stages of wood-based panels. Build Environ 47:197-204

Hrabalova M, Schwanninger M, Wimmer R, Gregorova A, Zimmermann T, Mundigler N (2011) Fibrillation of flax and wheat straw cellulose: effects on thermal, morphological, and viscoelastic properties of poly(vinylalcohol)/fibre composites. Bio Res 6:1631-1647

Ibrahim MNM, Ghani AM, Zakaria N, Shuib S, Sipaut CS (2008) Formulation of an environmentally friendly adhesive for wood. Macro Mol Symp 274:37-42

Imam SH, Gordon SH, Mao LJ, Chen L (2001) Environmentally friendly wood adhesive from a renewable plant polymer: characteristics and optimization. Polym Degrad Stab 73:529-533

Kajaks J, Reihmane S, Grinbergs U, Kalnins K (2012) Use of innovative environmentally friendly adhesives for wood veneer bonding. Proc Estonian Act 61:207-211

Kim S (2009) Environment-friendly adhesives for surface bonding of wood-based flooring using natural tannin to reduce formaldehyde and TVOC emission. Bioresour Technol 100:744-748

Laigle Y, Kamoun C, Pizzi A (1998) Particleboard IB forcast by TMA bending in UF adhesives curing. Holz Roh Werkst 56:154-154

Lei H, Pizzi A, Du GB (2008) Environmentally friendly mixed tannin/ lignin wood resins. J Appl Polym Sci 107:203-209

Li K, Geng X, Simonsen J, Karchesy J (2004) Novel wood adhesives from condensed tannins and polyethylenimine. Int $\mathrm{J}$ Adhes Adhes 24:327-333

Moubarik A, Charrier B, Allal A, Charrier F, Pizzi A (2010) Development and optimization of a new formaldehyde-free cornstarch and tannin wood adhesive. Eur J Wood Wood Prod 68:167-177

Patel DS, Toliwal SD, Patel JV (2012) Eco-friendly adhesives based on tannin and N, N-bis(2-hydroxy-ethyl) fatty amides (HEFAs) from non-traditional oils for wood bonding. J Adhes Sci Technol 26: 2217-2227

Pichelin F, Nakatani M, Pizzi A, Wieland S, Despres A, Rigolet S (2006) Structural beams from thick wood panels bonded industrially with formaldehyde-free tannin adhesives. Forest Prod J 56:31-36

Ping L, Brosse N, Chrusciel L, Navarrete P, Pizzi A (2011) Extraction of condensed tannins from grape pomace for use as wood adhesives. Ind Crops Prod 33:253-257

Ping L, Pizzi A, Guo ZD, Brosse N (2012) Condensed tannins from grape pomace: characterization by FTIR and MALDI TOF and production of environment friendly wood adhesive. Ind Crop Prod 40:13-20

Pizzi A (2000) Tannery row - the story of some natural and synthetic wood adhesives. Wood Sci Technol 34:277-316

Pizzi A, Vonleyser EP, Valenzuela J, Clark JG (1993a) The chemistry and development of pine tannin adhesives for exterior particleboard. Holzforschung 47:168-174

Pizzi A, Dombo B, Roll W (1993b) German Pat Appl P4402:159.3

Richter K, Bordeanu N, Opez-Suevos FL, Zimmermann T. Performance of cellulose nanofibrils in wood adhesives. Proceedings of the Swiss Bonding. Rapperswil, Switzerland. 2009:239-246.

Ruffing TC, Smith PM, Brown NR (2010) Resin suppliers' perspectives on the "greening" of the North American interior wood composite panel market. Forest Prod J 60:119-125

Sari B, Nemli G, Bardak S, Baharoglu M, Zekovic E (2010) Effects of formaldehyde/urea mole ratio, panel density, shelling ratio, and waste screen dust on the physical and mechanical properties, and 
formaldehyde emission of particleboard composite. High Temp Mater Process 29:287-294

Stoeckel F, Konnerth J, Gindl-Altmutter W (2013) Mechanical properties of adhesives for bonding wood - a review. Int J Adhes Adhes 45:32-41

Takemura A (2010) Wood adhesion - the past 10 years and the future. Mokuzai Gakkaishi 56:61-66
Veigel S, Rathke J, Weigl M, Gindl-Altmutter W Particle board and oriented strand board prepared with nanocellulose-reinforced adhesive J. Nanomater. 2012(Article ID 1585038 pages)

Zimmermann T, Bordeanu N, Strub E (2010) Properties of nanofibrillated cellulose from different raw materials and its reinforcement potential. Carbohyd Poly 79:1086-1093 